\title{
SYSTEMISCH DENKEN
}

Liebe Leserin, lieber Leser,

2018 werden wohl rund 1,5 Milliarden Fahrzeuge über die Straßen dieser Welt rollen - eine Verdoppelung innerhalb von nur einer Dekade. Daher kommt der sich aus dem Energiebedarf und dem Energiemix ergebenden $\mathrm{CO}_{2}$-Belastung eine immer größere Bedeutung zu. Dies gilt umso mehr, als die Klimagasemissionen in den letzten Jahren in allen Sektoren außer im Bereich Verkehr deutlich gesenkt werden konnten. Zwar hat die Industrie vor allem bei der innermotorischen Emissionsvermeidung und beim Leichtbau erhebliche Anstrengungen unternommen. Auch antriebstechnisch sind die Weichen gestellt: Kleine, hocheffiziente Motoren haben sich längst durchgesetzt, verbrennungsmotor-elektrische und elektrische Antriebe stehen in den Startlöchern. Letztere werden wohl aber erst ab 2030 einen nennenswerten Anteil an der Gesamtfahrleistung ausmachen.

Das bedeutet, dass Verbrennungsmotoren zumindest in den kommenden 20 Jahren noch eine herausragende Stellung einnehmen werden. Es besteht aber weiterhin eine große Abhängigkeit von fossilen Energieträgern. Mithin ist ein systemischer Ansatz vonnöten, der die Entwicklung der gesamten Energiekette von der Quelle bis zum Rad betrachtet. Nun sind auch Biokraftstoffe nicht in jedem Fall der Weisheit letzter Schluss. Hier gilt es, die $\mathrm{CO}_{2}$-Emissionen in der gesamten Erzeugungskette in Augenschein zu nehmen.

Eine Lösung könnte in alternativen Kraftstoffen aus anderen regenerativen Quellen liegen. Der steigende Anteil regenerativer Energie im Stromnetz allein ermöglicht noch keinen relevanten Beitrag zum Klimaschutz im Verkehr. Wird elektrische Energie im Verkehr genutzt, sind zusätzliche Kapazitäten regenerativen Stroms notwendig. Damit könnten zukünftig gasförmige oder flüssige Kraftstoffe synthetisch aus regenerativer elektrischer Energie hergestellt werden. Dieser Ansatz steckt zwar noch in den Kinderschuhen oder ist gar noch $\mathrm{Zu}$ kunftsmusik. Kraftstoffe dieser Art sind aber deshalb besonders interessant und zukunftsweisend, weil sie eine wirkliche Alternative darstellen.

Nur auf diese Weise - mit einem konsequent systemischen Ansatz, bei dem Antrieb und Kraftstoff zusammenwirken - können die wichtigen Klimaziele auch wirklich erreicht werden.

\section{Herzlichst, Ihr}

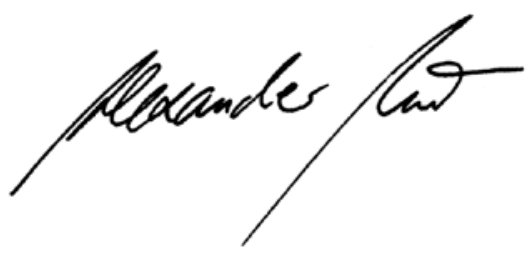

DR. ALEXANDER HEINTZEL, Chefredakteur Wiesbaden, 7. Februar 2013

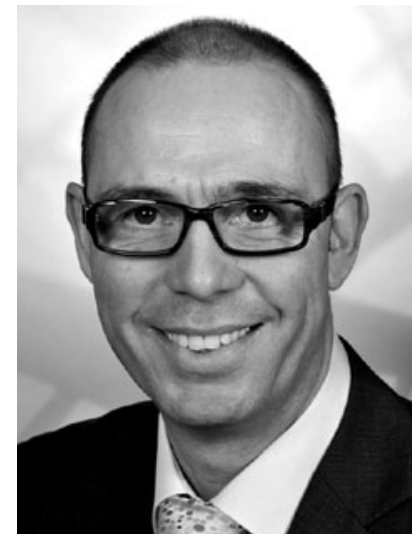

\section{Sicher unter Druck}

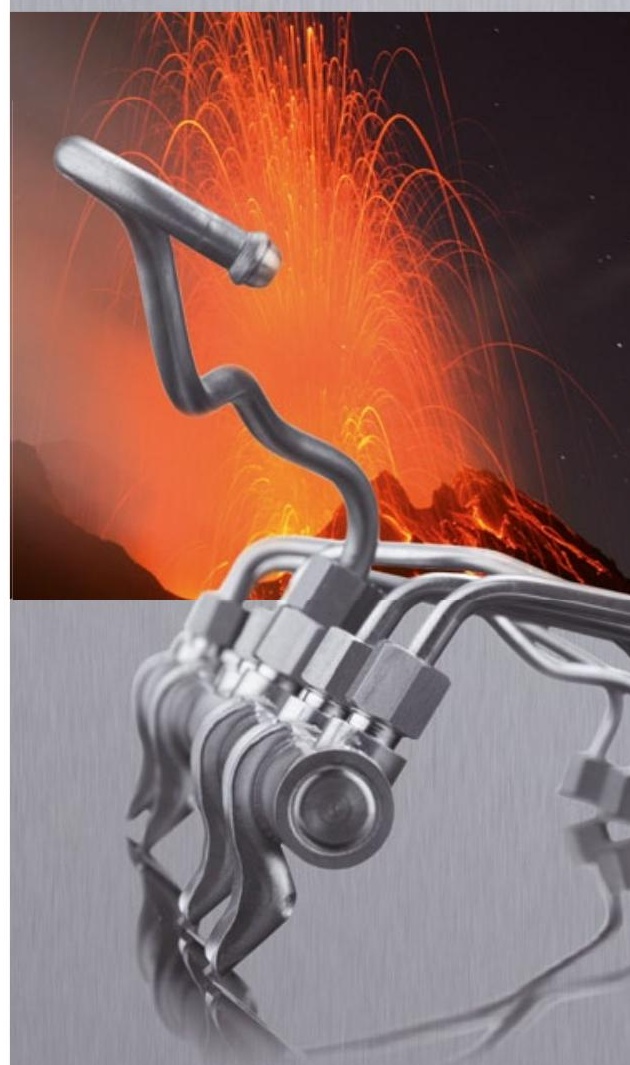

Die Kraftstoffgallerie mit ultimativer

Verbindungsicherheit zwischen den

Komponenten durch One-Piece-

Design.

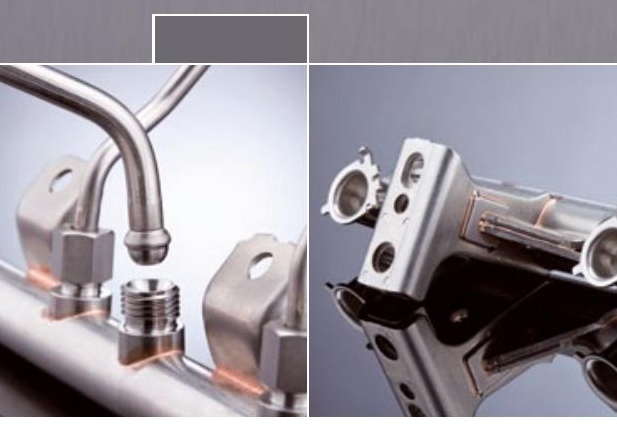

Winkelmann

Powertrain Components 